\title{
Desenvolvimento e produtividade da cana-de-açúcar após aplicação de reguladores vegetais em meio de safra
}

\author{
Development and yield of sugarcane after application of plant \\ growth regulators in the midle of crop season
}

\author{
Glauber Henrique Pereira Leite ${ }^{1}$; Carlos Alexandre Costa Crusciol'; \\ Marcelo de Almeida Silva ${ }^{3 *}$
}

\begin{abstract}
Resumo
O fornecimento de matéria-prima de qualidade tecnológica que garanta retorno econômico é uma das maiores necessidades da indústria sucroalcooleira. O objetivo do trabalho foi avaliar o desenvolvimento e a produtividade de colmos de cana-de-açúcar decorrente da aplicação de reguladores vegetais no meio da safra. O delineamento experimental utilizado foi o de blocos casualizados, com cinco repetições. Foram utilizados cinco tratamentos constituídos pela aplicação dos reguladores vegetais da classe dos retardantes de crescimento etefon e etil-trinexapac, e de $\mathrm{KNO}_{3}$ e $\mathrm{KNO}_{3}$ + Boro e uma testemunha (maturação natural). O etil-trinexapac e o etefon atuaram de forma eficiente em retardar o processo de crescimento em altura das plantas de cana-de-açúcar, sem ocasionar alterações no diâmetro dos colmos. A manutenção da integridade da gema apical possibilitou o incremento no diâmetro dos colmos sem interromper o crescimento em altura das plantas. Os maturadores propiciaram, conforme a época de aplicação, melhoria na qualidade tecnológica da matéria-prima. Ainda, não afetaram o número de colmos na colheita, não produziram alterações quantitativas na massa de colmos por hectare, e não afetaram a rebrora da soqueira da cana-de-açúcar.
\end{abstract}

Palavras-chave: Saccharum spp., maturadores, etefon, etil-trinexapac, biometria, produção

\begin{abstract}
The supply of technological quality raw material for providing economical return is the most important necessity of sugar and alcohol industry. The objective of this work was to evaluate the development and productivity of sugarcane stalks due to plant regulators application at half crop. The experiment was carried out in a randomized block design with five replications. The treatments consisted of four plant regulators of the class of the growth retainers (Ethephon, Ehyl-trinexapac, Potassium nitrate, Potassium nitrate + Boron) application and a control (natural ripening). Ethyl-trinexapac and Ethephon treatments were efficient to hold up growth process regarding height of plants, but had no effect on diameter of stalks. The maintenance of bud top integrity made possible the increase in diameter of stalks, without interrupting the growth process regarding height of plants. According to application time the ripeners provided improvement on technological quality of raw material. The ripeners did not affect the number of plants per meter at harvest and did not cause quantitative alterations in the mass of stalks per hectare. The ripeners did not affect the regrowth of the ratoon cane.
\end{abstract}

Key words: Saccharum spp., ripeners, ethephon, ethyl-trinexapac, biometrics, productivity

\footnotetext{
${ }^{1}$ Eng $^{\mathrm{o}}$. Agro . da Universidade Estadual Paulista, Faculdade de Ciências Agronômicas, Departamento de Produção Vegetal, Caixa Postal 237, CEP 18603-970 Botucatu, SP. E-mail: ghpleite@fca.unesp.br

2 Prof. da Universidade Estadual Paulista, Faculdade de Ciências Agronômicas, Departamento de Produção Vegetal, Caixa Postal 237, CEP 18603-970 Botucatu, SP. E-mail: crusciol@fca.unesp.br

${ }^{3}$ Pesquisador Científico. Agência Paulista de Tecnologia dos Agronegócios, Polo Centro Oeste, Caixa Postal 66, CEP 17201-970 Jaú, SP, Brasil. E-mail: marcelosilva@apta.sp.gov.br

* Autor para correspondência
} 


\section{Introdução}

O Brasil, atualmente, tem posição de destaque na liderança mundial no campo da agricultura energética, sendo a cana-de-açúcar uma das protagonistas deste quadro de sucesso, uma vez que destaca-se como líder nas agroindústrias de açúcar e etanol.

A produtividade agrícola da cana-de-açúcar teve aumentos expressivos no país decorrente de novas cultivares, manejo mais adequado do solo, uso de resíduos agroindustriais, aplicação racional de adubos e corretivos, expansão da safra, redução dos custos fixos, diversificação açúcar/etanol e a utilização de maturadores químicos permitindo a antecipação positiva da qualidade da matéria-prima (CARVALHO, 2004).

O fornecimento de matéria-prima de qualidade tecnológica a fim de propiciar extração econômica é uma das maiores necessidades da indústria sucroalcooleira. No entanto, em algumas regiões do país as condições climáticas no início e final da safra favorecem o desenvolvimento vegetativo em detrimento do acúmulo de sacarose, implicando em consequências negativas ao processo de maturação natural (RODRIGUES, 1995).

Técnicas agrícolas para melhorar a qualidade tecnológica da matéria-prima destinada à indústria têm sido adotadas, dentre elas, a aplicação de reguladores vegetais. Os maturadores, definidos como reguladores vegetais, referem-se a compostos químicos capazes de modificar a morfologia e a fisiologia vegetal. Estes compostos podem ser aplicados em diferentes épocas (início, meio ou final da safra), com a propriedade de paralisar e/ou retardar o desenvolvimento vegetativo da cana-deaçúcar induzindo a translocação e armazenamento dos açúcares, principalmente sacarose, podendo ocasionar modificações qualitativas e quantitativas na produção (CASTRO, 1999), sendo utilizados como instrumento auxiliar no planejamento da colheita e no manejo varietal (CAPUTO et al., 2008).
Comumente administrados no início da safra, os maturadores também poderiam ser administrados no meio e final da safra, buscando-se melhorar a qualidade da matéria-prima em caso de condições climáticas não favoráveis à maturação natural ou ampliar o período de moagem aliado à garantia de fornecimento de matéria-prima de qualidade à indústria

A aplicação de maturadores tem propiciado, mesmo sob condições climáticas desfavoráveis ao processo de maturação, a industrialização de matéria-prima de qualidade (ALMEIDA; LEITE; SOUZA, 2005; LEITE et al., 2008, 2009). Dentre os agentes químicos utilizados como maturadores destacam-se o etefon, o etil-trinexapac, o glifosato e o sulfometuron metil. Atualmente, produtos cuja composição química apresentam o nitrato de potássio têm sido empregados nas lavouras de cana-de-açúcar com a mesma finalidade, associado à vantagem de serem menos agressivos ao meio ambiente, podendo substituir o uso de herbicidas, quando houver nas proximidades da cultura da cana-de-açúcar, culturas sensíveis ao modo de ação destes outros produtos químicos (HARO et al., 2001).

Apesar dos efeitos positivos na qualidade da matéria-prima, alguns reguladores de crescimento utilizados como maturadores podem ter efeito prejudicial na produtividade do ciclo em que foi aplicado o maturador (CAPUTO et al., 2007) ou na soqueira seguinte (LEITE; CRUSCIOL, 2008), devido à propriedade de paralisar e/ou retardar o desenvolvimento vegetativo da cana-de-açúcar. Por outro lado, Silva et al. (2007) aplicaram etefon como maturador e relataram aumento do perfilhamento em dois dos três genótipos até 180 dias durante a soqueira seguinte, entretanto sem benefícios ou prejuízos à produtividade.

Portanto, a finalidade deste trabalho foi avaliar o desenvolvimento e a produtividade de colmos da cultivar SP80-3280 de cana-de-açúcar decorrente da aplicação de reguladores vegetais da classe dos retardadores de crescimento no meio da safra. 


\section{Material e Métodos}

O experimento foi conduzido em cana soca ( $1^{\circ}$ corte realizado em $21 / 10 / 2003$ ) por dois anos consecutivos (2004 e 2005) na Fazenda Bosque, no município de Igaraçu do Tietê, Estado de São Paulo (latitude de $22^{\circ} 38^{\prime} 45^{\prime} \mathrm{S}$, longitude $48^{\circ}$ 36' 29' W e altitude de $620 \mathrm{~m})$ pertencente ao GRUPO COSAN - Unidade Barra (Usina da Barra). O clima predominante da região é o Aw
(Köppen), com clima seco definido, temperatura média anual de $21,6^{\circ} \mathrm{C}$, umidade relativa média de $70 \%$, com extremos de $77 \%$ em fevereiro e $59 \%$ em agosto, sendo a precipitação pluvial média de $1.344 \mathrm{~mm}$. Os dados climáticos mensais, referentes às temperaturas máxima, média e mínima, precipitação pluvial e velocidade do vento durante o período de condução do experimento, coletados na Estação Meteorológica da Fazenda São Joaquim, são apresentados na (Figura 1).

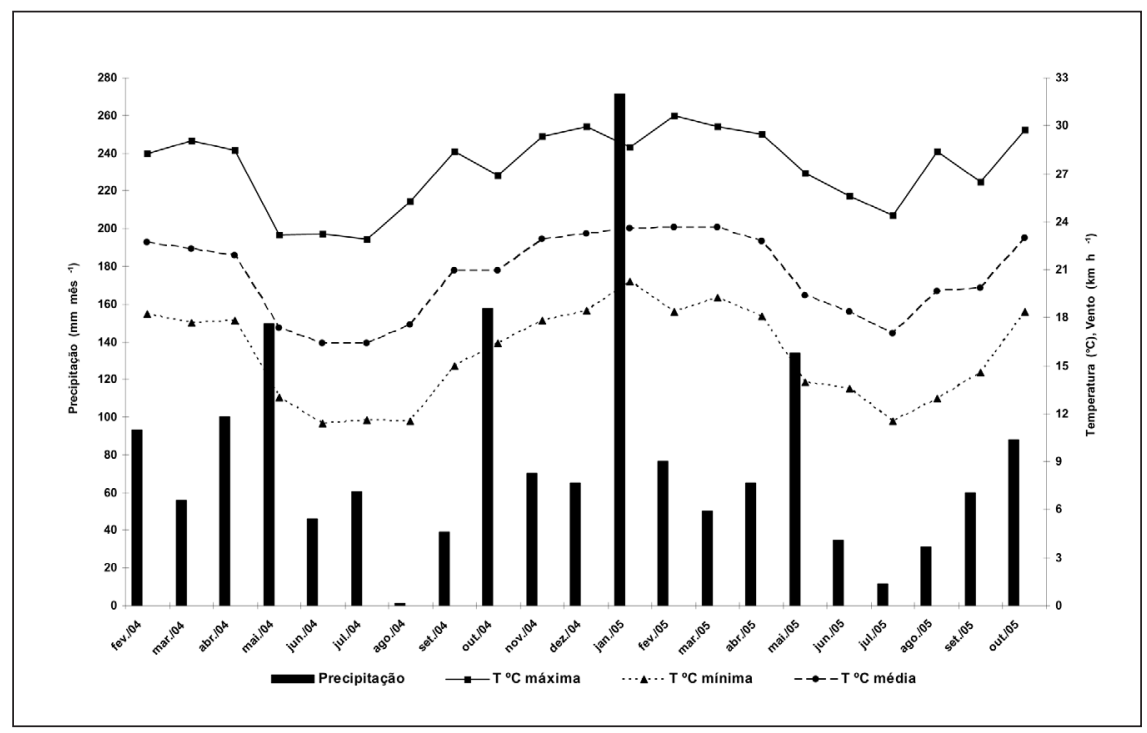

Figura 1. Precipitação $\left(\mathrm{mm}\right.$ mês $\left.{ }^{-1}\right)$, temperaturas máxima, média e mínima $\left({ }^{\circ} \mathrm{C}\right)$ registradas durante o período de condução do experimento na Estação Metereológica da Fazenda São Joaquim na safra 2004 e na safra 2005, Igaraçu do Tietê, SP.

A área foi plantada com a cultivar SP80-3280, que tem como características elevado teor de sacarose e produtividade em soqueira, moderado perfilhamento, maturação média para tardia, boa brotação de soqueiras, florescimento e pouco chochamento, além de ser uma das variedades mais cultivadas na região Centro-Sul do Brasil (SANTOS et al., 2008). O delineamento experimental foi em blocos casualizados, com cinco repetições. Os tratamentos foram constituídos da aplicação de quatro reguladores vegetais da classe dos retardadores do crescimento (etefon, etil-trinexapac, $\mathrm{KNO}_{3}$ e $\mathrm{KNO}_{3}+$ Boro) e uma testemunha (maturação natural), comercialmente encontrados como Ethrel, Moddus, Krista Kana e Krista Kana Plus. As doses de etefon, etil-trinexapac, $\mathrm{KNO}_{3}$ e $\mathrm{KNO}_{3}+$ Boro foram respectivamente de $2 \mathrm{~L} \mathrm{ha}^{-1}, 0,8 \mathrm{~L} \mathrm{ha}^{-1}, 3 \mathrm{~kg}$ $\mathrm{ha}^{-1}$ e $3 \mathrm{~kg} \mathrm{ha}^{-1}$, todos sem adição de adjuvantes. Cada parcela foi constituída por oito linhas de 10 $\mathrm{m}$ de comprimento, espaçadas de $1,5 \mathrm{~m}$, contudo para as avaliações foram consideradas as seis linhas centrais, desprezando $1 \mathrm{~m}$ nas extremidades, perfazendo uma área útil de $72 \mathrm{~m}^{2}$.

A aplicação dos maturadores foi realizada em $10 / 05 / 2004$ e $04 / 08 / 2005$ por meio de equipamento costal pressurizado $\left(\mathrm{CO}_{2}\right)$ com barra de $6 \mathrm{~m}$ de comprimento, em forma de $\mathrm{T}$, contendo seis pontas de pulverização AXI 11002, em pressão de trabalho de 50 PSI e o volume de calda de $100 \mathrm{~L} \mathrm{ha}^{-1}$. 
A produtividade de colmos (TCH), por ocasião da colheita, foi determinada nas quatro linhas centrais e, em duas linhas de plantas foram destinadas à análise tecnológica para mensuração de açúcares redutores totais (ART), realizada aos $0,15,30,45$, 60, 75, 90 e 174 dias após aplicação (DAA) em 2004 e aos $0,15,30,60$ e 90 DAA em 2005. Dez colmos foram coletados por meio do desponte na altura da gema apical e após desfolha, encaminhados para o laboratório de Bebidas do Departamento de Gestão e Tecnologia Agroindustrial da Faculdade de Ciências Agronômicas (FCA/UNESP), Botucatu-SP. A metodologia utilizada foi do Sistema de Pagamento de Cana pelo Teor de Sacarose (SPCTS), conforme atualizações semestrais da Consecana, quanto às avaliações tecnológicas descritas em Fernandes (2003), sendo considerado o parâmetro açúcares redutores totais cana (ART).

Nas mesmas plantas destinadas à avaliação tecnológica também foram quantificadas, aos 0 e 90 DAA, as variáveis altura de plantas e diâmetro de colmos. A altura foi determinada da superfície do solo até a região auricular da folha +1 , de acordo com a numeração sugerida por Kuijper (DILLEWIJN, 1952), enquanto o diâmetro foi determinado no $3^{\circ}$ entrenó acima da superfície do solo, com o auxílio de paquímetro digital.

$\mathrm{Na}$ colheita determinou-se, ainda, o número de colmos, enquanto a rebrota da soqueira foi quantificada aos 45 dias após a colheita (DAC). Ambos os parâmetros foram avaliados em 10 $\mathrm{m}$ de linha dentro da área útil de cada parcela e, posteriormente, foi estabelecido os respectivos valores por metro.

Os resultados foram submetidos à análise de variância e as médias dos tratamentos comparadas pelo teste LSD a 5\% de probabilidade. Os resultados de épocas de amostragem foram submetidos à análise de regressão, adotando-se como critério para escolha do modelo a magnitude dos coeficientes de regressão significativos a $5 \%$ de probabilidade pelo teste $\mathrm{t}$.

\section{Resultados e Discussão}

Em 2004, a disponibilidade hídrica e temperaturas foram favoráveis ao desenvolvimento vegetativo das plantas de cana-de-açúcar, havendo diminuição da precipitação pluvial e declínio da temperatura a partir dos meses de julho e abril, respectivamente (Figura 1). Todavia, em 2005, a menor disponibilidade hídrica e térmica favoreceram o processo de maturação natural (Figura 1). A planta de cana-de-açúcar, na fase de maturação, exige temperaturas baixas, abaixo de $20^{\circ} \mathrm{C}$ e/ou déficit hídrico para que haja repouso fisiológico e, consequente, maior acúmulo de sacarose nos colmos (ANDRADE, 2006).

Em 2004, os tratamentos $\mathrm{KNO}_{3}+$ Boro e etiltrinexapac foram eficientes em retardar o processo de crescimento em altura das plantas de cana-deaçúcar (Tabela 1). Enquanto em 2005, as plantas tratadas com etil-trinexapac e etefon apresentaram mesmo comportamento (Tabela 1), corroborando com outros resultados encontrados na literatura (HARO et al., 2001; LEITE et al., 2009).

Estes resultados podem ser explicados, possivelmente, pelo menor alongamento dos entrenós imaturos derivados da aplicação de etiltrinexapac ou do etefon, atuando de forma a reduzir o nível endógeno de giberelina ou consequencia da maior concentração de etileno na planta, respectivamente. Embora com ação indireta em promover a síntese de etileno, provavelmente em 2004 o efeito do $\mathrm{KNO}_{3}+$ Boro foi consequência da maior altura das plantas mensurada na instalação do experimento, diferindo dos demais tratamentos (Tabela 1). 
Tabela 1. Altura de plantas e diâmetro dos colmos de cana-de-açúcar cultivar SP80-3280, sob efeito dos maturadores aos 0 e 90 dias após a aplicação (DAA). Igaraçu do Tietê, SP, 2004/2005.

\begin{tabular}{|c|c|c|c|c|}
\hline \multirow{3}{*}{ Tratamentos } & \multicolumn{4}{|c|}{ Altura de plantas $(\mathrm{m})^{1}$} \\
\hline & \multicolumn{2}{|c|}{2004} & \multicolumn{2}{|c|}{2005} \\
\hline & $0 \mathrm{DAA}$ & $90 \mathrm{DAA}$ & $0 \mathrm{DAA}$ & 90 DAA \\
\hline Testemunha & $2,53 \mathrm{bB}$ & $2,88 \mathrm{aA}$ & $2,28 \mathrm{aB}$ & $2,40 \mathrm{aA}$ \\
\hline $\mathrm{KNO}_{3}+$ Boro & $2,79 \mathrm{aA}$ & $2,82 \mathrm{aA}$ & $2,25 \mathrm{aB}$ & $2,40 \mathrm{aA}$ \\
\hline $\mathrm{KNO}_{3}$ & $2,65 \mathrm{abB}$ & $2,83 \mathrm{aA}$ & $2,23 \mathrm{aB}$ & $2,42 \mathrm{aA}$ \\
\hline Etil-trinexapac & $2,65 \mathrm{abA}$ & $2,79 \mathrm{aA}$ & $2,34 \mathrm{aA}$ & $2,38 \mathrm{aA}$ \\
\hline Etefon & $2,70 \mathrm{abB}$ & $2,93 \mathrm{aA}$ & $2,25 \mathrm{aA}$ & $2,35 \mathrm{aA}$ \\
\hline \multirow[t]{2}{*}{ CV (\%) } & \multicolumn{2}{|c|}{4,85} & \multicolumn{2}{|c|}{4,63} \\
\hline & \multicolumn{4}{|c|}{ Diâmetro de colmos $(\mathrm{mm})^{1}$} \\
\hline \multirow{2}{*}{ Tratamentos } & \multicolumn{2}{|c|}{2004} & \multicolumn{2}{|c|}{2005} \\
\hline & 0 DAA & $90 \mathrm{DAA}$ & $0 \mathrm{DAA}$ & $90 \mathrm{DAA}$ \\
\hline Testemunha & $28,09 \mathrm{aA}$ & $28,23 \mathrm{aA}$ & $25,79 \mathrm{aB}$ & $28,31 \mathrm{aA}$ \\
\hline $\mathrm{KNO}_{3}+$ Boro & $27,57 \mathrm{aA}$ & $29,88 \mathrm{aA}$ & $25,15 \mathrm{aA}$ & $26,99 \mathrm{abA}$ \\
\hline $\mathrm{KNO}_{3}$ & $27,26 \mathrm{aA}$ & $29,18 \mathrm{aA}$ & $25,63 \mathrm{aA}$ & $27,13 \mathrm{abA}$ \\
\hline Etil-trinexapac & $28,28 \mathrm{aA}$ & $29,05 \mathrm{aA}$ & $26,17 \mathrm{aA}$ & $26,99 \mathrm{abA}$ \\
\hline Etefon & $27,95 \mathrm{aA}$ & $28,00 \mathrm{aA}$ & $25,54 \mathrm{aA}$ & $26,14 \mathrm{bA}$ \\
\hline $\mathrm{CV}(\%)$ & \multicolumn{2}{|c|}{4,43} & \multicolumn{2}{|c|}{5,49} \\
\hline
\end{tabular}

${ }^{1}$ Médias seguidas de letras distintas, minúscula na coluna e maiúscula na linha, diferem estatisticamente pelo teste de $\mathrm{DMS}$ ( $\left.\mathrm{P}=0,05\right)$.

As giberelinas atuam promovendo o alongamento celular, por favorecer o aumento da extensibilidade da parede celular (TAIZ; ZEIGER, 2004). O etiltrinexapac reduz os níveis endógenos da forma ativa de giberelina ácida $\mathrm{GA}_{1}$, a qual refere-se a giberelina de maior eficiência biológica, sendo constatado inibição no alongamento do colmo (TYMOWSKALALANNE; KREIS, 1998; RESENDE; SOARES; HUDETZ, 2001; TAIZ; ZEIGER, 2004).

O etefon é um regulador vegetal, o qual aplicado via foliar, é mantido estável através de $\mathrm{pH}$ menor ou igual a 3,5, perdendo essa estabilidade no contato com o tecido vegetal ( $\mathrm{pH}$ próximo da neutralidade), que causa a liberação de etileno gasoso $\left(\mathrm{C}_{2} \mathrm{H}_{4}\right)$, o qual penetra no tecido vegetal. Dentro do tecido é translocado progressivamente, levando à paralização temporária do crescimento vegetativo do meristema apical. No entanto, colmo retoma o crescimento apical gradativamente, devido a diminuição progressiva do teor de etileno presente nos meristemas (TAIZ; ZEIGER, 2004).

$\mathrm{O} \mathrm{KNO}_{3}$ embora não tenha efeito herbicida apresenta eficácia indireta no processo de crescimento em altura das plantas (HARO et al., 2001), isto é, sua aplicação consiste em dano químico, o qual tem influência sobre a biossíntese de etileno (TAIZ; ZEIGER, 2004).

Os tratamentos não induziram alterações no diâmetro dos colmos em 2004 (Tabela 1). Em 2005, a manutenção da integridade da gema apical no tratamento Testemunha implicou no incremento significativo do valor de diâmetro dos colmos entre épocas, diferindo do tratamento com etefon aos 90 DAA (Tabela 1). Os resultados concordam com Almeida, Leite e Souza (2005), os quais relataram sinais leves de injúria às plantas de cana provocados pelo maturador etefon, havendo amarelecimento das folhas centrais do cartucho, encurtamento e redução da expansão lateral dos entrenós, com posterior recuperação e retomada do desenvolvimento.

Este resultado pode ser explicado, provavelmente, pelas condições climáticas (Figura 1) e pelo equilíbrio hormonal entre a auxina, componente do controle da dominância da gema 
apical, e o ácido abscísico (ABA), característico em plantas submetidas à estresse hídrico. Nesse sentido, a síntese de auxina, dada pela manutenção da integridade da gema apical, é capaz de promover o aumento da extensibilidade e o alongamento celular, enquanto o ABA, aparentemente, promove o fechamento estomático e aumenta o influxo de água e íons para as raízes, tendo em vista que o crescimento das células é um processo irreversível que requer absorção de água, estiramento permanente e síntese de parede (TAIZ; ZEIGER, 2004).

O aumento do teor de ART (Figuras 2A e 2B) com o transcorrer das épocas de amostragem, provavelmente foi decorrente da maior influência que a sacarose apresenta sobre os açúcares totais, uma vez que durante o processo de maturação há redução da intensidade de crescimento, responsável pela demanda de glicose e frutose, e consequente acúmulo de sacarose na planta.

Em 2004, os tratamentos apresentaram resposta expressa por modelo quadrático crescente (Figura 2A), porém, no ano subsequente ajustaram-se à modelo linear positivo, exceto o tratamento com Etefon (Figura 2B). Os maiores teores de ART, em ordem decrescente, foram alcançados com etefon $(17,00 \%), \mathrm{KNO}_{3}+$ Boro $(16,90 \%), \mathrm{KNO}_{3}$ $(16,80 \%)$, etil-trinexapac $(16,60 \%)$ e testemunha $(16,40 \%)$ aos $134,124,152,129$ e 138 DAA, respectivamente (Figura 2A). De forma semelhante, Caputo et al. (2007) concluíram que diversos genótipos de cana-de-açúcar responderam de forma significativa em relação ao acúmulo de sacarose por meio da aplicação de etefon.

Os ART representam todos os açúcares da cana na forma de açúcares redutores ou invertidos, embora outras substâncias redutoras presentes no caldo de cana possam estar incluídas. Na planta, o desdobramento da sacarose em glicose e frutose é uma reação de duplo sentido, isto é, ocorre a inversão assim como a combinação durante o metabolismo da fotossíntese e respiração da planta, sendo importante o conhecimento do teor de ART para avaliação da qualidade da matéria-prima, principalmente aquela destinada à produção de etanol (FERNANDES, 2003). A aplicação dos maturadores em 10/05/2004 induziu incrementos significativos quanto ao acúmulo de sacarose nos colmos em relação à testemunha (Figura 2A), provavelmente o modo de ação destes produtos químicos foi favorecido pelas condições climáticas favoráveis ao desenvolvimento vegetativo da canade-açúcar (Figura 1). A aplicação dos tratamentos etefon, $\mathrm{KNO}_{3}$ e $\mathrm{KNO}_{3}$ + Boro em 04/08/2005 pouco influenciou o processo de maturação (Figura 2B), provavelmente devido as condições climáticas favoráveis ao acúmulo de sacarose (Figura 1) e do controle genético varietal responsável pela regulação do processo, todavia, nesta época o maturador etil-trinexapac foi eficiente em induzir tal processo (Figura 2B). Segundo TymowskaLalanne e Kreis (1998) e Resende; Soares e Hudetz (2001), o maturador etil-trinexapac tem ação efetiva em promover a inibição no alongamento do colmo e possíveis mudanças na partição de fotoassimilados, favorecendo o acúmulo de sacarose.

O número de colmos por metro determinado na colheita do experimento não sofreu influência dos tratamentos (Tabela 2).

Os tratamentos não induziram alterações quantitativas na produtividade de colmos da canade-açúcar (Tabela 2). Em 2004, os tratamentos que proporcionaram a maior massa de colmos por hectare, em ordem crescente, foram o etil-trinexapac, etefon, testemunha, $\mathrm{KNO}_{3}$ e $\mathrm{KNO}_{3}+$ Boro. $\mathrm{Na}$ safra subsequente foram etefon, etil-trinexapac, testemunha, $\mathrm{KNO}_{3}+$ Boro e $\mathrm{KNO}_{3}$. Alguns relatos na literatura têm enfatizado que a aplicação de etefon em cultivares de cana-de-açúcar tanto no início quanto no meio da safra não ocasionou efeitos prejudiciais na produção de cana-de-açúcar (CASTRO et al., 2001; CASTRO et al., 2002; CAPUTO et al., 2007; LEITE et al.; 2008). 


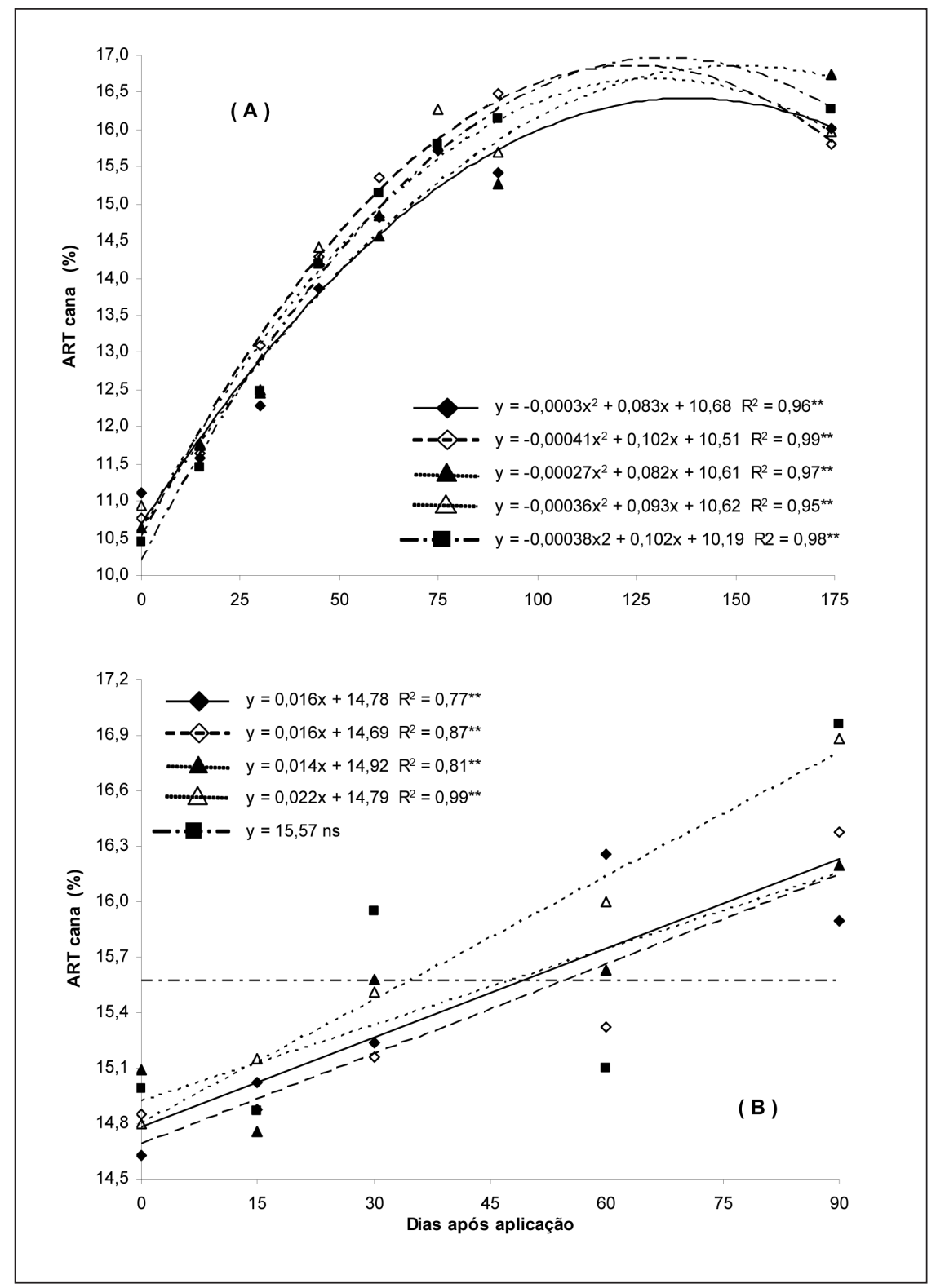

Figura 2. Açúcares redutores totais (ART, \%) em função da aplicação dos tratamentos testemunha $(--), \mathrm{KNO}_{3}+$ Boro $[-\prec-], \mathrm{KNO}_{3}(--\mathbf{A}--]$, Etil-trinexapac $[--\triangle--]$ e Etefon [--- - $]$ na variedade de cana-de-açúcar SP80-3280, Igaraçu do Tiête, SP, na safra 2004 (A) e na safra 2005 (B). * e ** são significativos a 5 e $1 \%$ de probabilidade pelo teste de DMS, respectivamente. 
Tabela 2. Número de colmos aos 90 dias após a aplicação (DAA), rebrota da soqueira aos 45 dias após a colheita (DAC) e produtividade de colmos na colheita da cana-de-açúcar cultivar SP80-3280 sob efeito dos maturadores. Igaraçu do Tietê, SP, 2004/2005.

\begin{tabular}{|c|c|c|}
\hline & \multicolumn{2}{|c|}{ Número de colmos $\left(\text { metro }^{-1}\right)^{1}$} \\
\hline Tratamentos & 2004 & 2005 \\
\hline Testemunha & $12,00 \mathrm{a}$ & $13,00 \mathrm{a}$ \\
\hline $\mathrm{KNO}_{3}+$ Boro & $12,00 \mathrm{a}$ & $13,00 \mathrm{a}$ \\
\hline $\mathrm{KNO}_{3}$ & $12,00 \mathrm{a}$ & $13,00 \mathrm{a}$ \\
\hline Etil-trinexapac & $12,00 \mathrm{a}$ & $13,00 \mathrm{a}$ \\
\hline Etefon & $13,00 \mathrm{a}$ & $13,00 \mathrm{a}$ \\
\hline \multirow[t]{2}{*}{$\mathrm{CV}(\%)$} & 5,17 & 4,04 \\
\hline & \multicolumn{2}{|c|}{ Produtividade de colmos $(\mathrm{t} \text { cana ha-1 })^{1}$} \\
\hline Tratamentos & 2004 & 2005 \\
\hline Testemunha & $110,60 \mathrm{a}$ & $85,30 \mathrm{a}$ \\
\hline $\mathrm{KNO}_{3}+$ Boro & $112,90 \mathrm{a}$ & $85,60 \mathrm{a}$ \\
\hline $\mathrm{KNO}_{3}$ & $111,70 \mathrm{a}$ & $87,30 \mathrm{a}$ \\
\hline Etil-trinexapac & $106,50 \mathrm{a}$ & $84,50 \mathrm{a}$ \\
\hline Etefon & $107,50 \mathrm{a}$ & $83,00 \mathrm{a}$ \\
\hline \multirow[t]{2}{*}{$\mathrm{CV}(\%)$} & 4,52 & 6,50 \\
\hline & \multicolumn{2}{|c|}{ Número de brotos $\left(\text { metro }^{-1}\right)^{1}$} \\
\hline Tratamentos & 2004 & 2005 \\
\hline Testemunha & $14,00 \mathrm{a}$ & $11,00 \mathrm{a}$ \\
\hline $\mathrm{KNO}_{3}+$ Boro & $13,00 \mathrm{a}$ & $12,00 \mathrm{a}$ \\
\hline $\mathrm{KNO}_{3}$ & $14,00 \mathrm{a}$ & $11,00 \mathrm{a}$ \\
\hline Etil-trinexapac & $14,00 \mathrm{a}$ & $11,00 \mathrm{a}$ \\
\hline Etefon & $14,00 \mathrm{a}$ & $11,00 \mathrm{a}$ \\
\hline CV $(\%)$ & 6,87 & 7,86 \\
\hline
\end{tabular}

${ }^{1}$ Médias seguidas de letras distintas, minúscula na coluna e maiúscula na linha, diferem estatisticamente pelo teste de DMS $(\mathrm{P}=0,05)$.

Os tratamentos não induziram diferenças significativas na contagem de brotos por metro realizada aos 45 DAC (Tabela 2). Estes resultados corroboram com Deuber e Irvine (1987), os quais afirmaram que a aplicação de etefon não afetou o perfilhamento da soqueira, assim como discordam de Silva et al. (2007) e Silva; Cato e Costa (2010), os quais relataram maior perfilhamento da soqueira de algumas variedades de cana-de-açúcar após a aplicação deste agente químico. Segundo Casagrande (1991), os produtores que adotam a prática de aplicação de maturadores em cana-deaçúcar têm por objetivo incrementar a qualidade tecnológica dos colmos, todavia sem afetar a produtividade e a brotação da soqueira.

\section{Conclusões}

Os maturadores etil-trinexapac e etefon atuam de forma eficiente em retardar o processo de crescimento em altura das plantas de cana-deaçúcar, sem ocasionar alterações no diâmetro dos colmos.

A manutenção da integridade da gema apical possibilita o incremento do diâmetro dos colmos sem interromper o crescimento em altura das plantas.

A melhoria na qualidade tecnológica da matériaprima pelos maturadores é influenciada pelas condições climáticas do ano agricola.

Os maturadores não afetam o número de colmos na colheita, assim como não produzem alterações quantitativas na massa de colmos por hectare. 
Os maturadores não afetam a rebrota da soqueira da cana-de-açúcar .

\section{Agradecimentos}

À Fundação de Amparo à Pesquisa do Estado de São Paulo (Fapesp), pela concessão de bolsa de estudo; ao CNPq pela concessão de bolsa de produtividade em pesquisa aos segundo e terceiro autores, e ao Grupo COSAN - Unidade Barra (Usina da Barra), pela permissão de realização do experimento em sua área experimental.

\section{Referências}

ALMEIDA, J. C. V.; LEITE, C. R. F.; SOUZA, J. R. P. Efeito de maturadores nas características tecnológicas da cana-de-açúcar com e sem estresse hídrico. Semina: Ciências Agrárias, Londrina, v. 26, n. 4, out./dez. 2005.

ANDRADE, L. A. de B. Cultura da cana-de-açúcar. In: CARDOSO, M. das G. (Ed.). Produção de aguardente de cana-de-açúcar. 2. ed. rev. e ampl. Lavras: UFLA, 2006. cap.1, p. 25-67.

CAPUTO, M. M.; BEAUCLAIR, E. G. F.; SILVA, M. A.; PIEDADE, S.M.S. Resposta de genótipos de cana-deaçúcar à aplicação de indutores de maturação. Bragantia, Campinas, v. 67, n. 1, p. 15-23, 2008.

CAPUTO, M. M.; SILVA, M. A.; BEAUCLAIR, E. G. F.; GAVA, G. J. C. Acúmulo de sacarose, produtividade e florescimento de cana-de-açúcar sob reguladores vegetais. Interciencia, Caracas, v. 32 , n. 12, p. 834-840, 2007.

CARVAlHO, L. C. C. Cana-de-açúcar, um mundo de oportunidades. Atualidades Agrícolas, São Paulo, v. 2, n. 1, abr. p. 4-9, 2004.

CASAGRANDE, A. A. Tópicos de morfologia e fisiologia da cana-de-açúcar. Jaboticabal: FUNEP, 1991. $157 \mathrm{p}$.

CASTRO, P. R. C. Maturadores químicos em cana-deaçúcar. Saccharum, Piracicaba, v. 1, n. 4, p. 12-16, 1999.

CASTRO, P. R. C.; MIYASAKI, J. M.; BEMARDI, M.; MARENGO, D.; NOGUEIRA, M. C. S. Efeito do Etefon na maturação e produtividade da cana-de-açúcar. Revista de Agricultuta, Piracicaba, v. 76, n. 2, p. 277-290, 2001.
CASTRO, P. R. C.; ZAMBON, S.; SANSÍDOLO, M. A.; BELTRAME, J. A.; NOGUEIRA, M. C. S. Ação comparada de Ethrel, Fuzilade e Glifosato, em duas épocas de aplicação, na maturação e produtividade da cana-de-açúcar, variedade SP 70-1143. Revista de Agricultura, Piracicaba, v. 77, n. 1, p. 23-38, 2002.

DEUBER, R.; IRVINE, J. E. Controle do florescimento da cana-de-açúcar com aplicação de Etefon. Boletim Técnico Copersucar, Piracicaba, v. 36, n. 84, p. 16-24, 1987.

DILLEWIJN, C. van. Botany of sugar cane. Waltham: Chronica Botanica, 1952. $371 \mathrm{p}$.

FERNANDES, A. C. Cálculos na agroindústria da canade-açúcar. 2 .ed. Piracicaba: STAB, 2003. 240 p.

HARO, M.; MAFLA, H.; FORS, A.; MÁRQUEZ, C. Aplicación de madurantes en canteros con riesgo por cultivos colindantes. Sugar Journal, New Orleans, v. 64, n. 10 , p. 12-21, 2001.

LEITE, G. H. P.; CRUSCIOL, C. A. C. Reguladores vegetais no desenvolvimento e produtividade da canade-açúcar. Pesquisa Agropecuária Brasileira, Brasília, v. 43, n. 8, p. 995-1001, 2008.

LEITE, G. H. P.; CRUSCIOL, C. A. C.; SILVA, M. A.; VENTURINI FILHO, W. G. Reguladores vegetais e qualidade tecnológica da cana-de-açúcar em meio de safra. Ciência e Agrotecnologia, Lavras, v. 32, n. 6, p. 1843-1850, 2008.

LEITE, G. H. P.; CRUSCIOL, C. A. C.; SILVA, M. A.; VENTURINI FILHO, W. G.; SURIANO, A. Qualidade tecnológica, produtividade e margem de contribuição agrícola da cana-de-açúcar em função da aplicação de reguladores vegetais no início da safra. Ciência Rural, Santa Maria, v. 39, n. 3, p. 726-732, 2009.

RESENDE, P. A. P.; SOARES, J. E.; HUDETZ, M. Moddus, a plant growth regulator and management tool for sugarcane production in Brazil. International Sugar Journal, London, v. 103, n. 1225, p. 2-6, 2001.

RODRIGUES, J. D. Fisiologia da cana-de-açúcar. Botucatu: Unesp, 1995. 75 p.

SANTOS, E. G. D.; CHAPOLA, R. G.; GONÇALVES, R. A.; MOUTA, E. R.; VIEIRA, M. A. S.; BASSINELLO, A. I.; HOFFMANN, H. P. Censo varietal 2007 de áreas canavieiras da região Centro-Sul. STAB - Açúcar Alcool e Subprodutos, Piracicaba, v. 26, n. 4, p. 42-46, 2008.

SILVA, M. A. CATO, S. C.; COSTA, A. G. F. Produtividade e qualidade tecnológica da soqueira de cana-de-açúcar submetida à aplicação de biorregulador e fertilizantes líquidos. Ciência Rural, Santa Maria, v. 40, n. 4, p. 774-780, 2010. 
SILVA, M. A.; GAVA, G. J. C.; CAPUTO, M. M.; PINCELLI, R. P.; JERÔNIMO, E. M.; CRUZ, J. C. S. Uso de reguladores de crescimento como potencializadores do perfilhamento e da produtividade em cana-soca. Bragantia, Campians, v. 66, n. 4, p. 545-552, 2007.
TAIZ, L.; ZEIGER, E. Fisiologia vegetal. 3. ed. Porto Alegre: Artmed, 2004.

TYMOWSKA-LALANE, Z.; KREIS, M. The plant invertases: physiology, biochemistry and molecular biology. Advances in Botany Research, Cambridge, v. 28, n. 1, p. 71-117, 1998. 